\title{
Social comparison affects reward-related brain activity in the human ventral striatum
}

Citation for published version (APA):

Fliessbach, K., Weber, B., Trautner, P., Dohmen, T. J., Sunde, U., Elger, C. E., \& Falk, A. (2007). Social comparison affects reward-related brain activity in the human ventral striatum. Science, 318(5854), 13051308. https://doi.org/10.1126/science.1145876

Document status and date:

Published: 01/01/2007

DOI:

10.1126/science. 1145876

Document Version:

Publisher's PDF, also known as Version of record

\section{Please check the document version of this publication:}

- A submitted manuscript is the version of the article upon submission and before peer-review. There can be important differences between the submitted version and the official published version of record.

People interested in the research are advised to contact the author for the final version of the publication, or visit the DOI to the publisher's website.

- The final author version and the galley proof are versions of the publication after peer review.

- The final published version features the final layout of the paper including the volume, issue and page numbers.

Link to publication

\footnotetext{
General rights rights.

- You may freely distribute the URL identifying the publication in the public portal. please follow below link for the End User Agreement:

www.umlib.nl/taverne-license

Take down policy

If you believe that this document breaches copyright please contact us at:

repository@maastrichtuniversity.nl

providing details and we will investigate your claim.
}

Copyright and moral rights for the publications made accessible in the public portal are retained by the authors and/or other copyright owners and it is a condition of accessing publications that users recognise and abide by the legal requirements associated with these

- Users may download and print one copy of any publication from the public portal for the purpose of private study or research.

- You may not further distribute the material or use it for any profit-making activity or commercial gain

If the publication is distributed under the terms of Article $25 \mathrm{fa}$ of the Dutch Copyright Act, indicated by the "Taverne" license above, 


\section{Science \\ MIAAAS}

Social Comparison Affects Reward-Related Brain Activity in the Human Ventral Striatum

K. Fliessbach, et al.

Science 318, 1305 (2007);

DOI: $10.1126 /$ science. 1145876

\section{The following resources related to this article are available online at www.sciencemag.org (this information is current as of April 23, 2008 ):}

Updated information and services, including high-resolution figures, can be found in the online version of this article at:

http://www.sciencemag.org/cgi/content/full/318/5854/1305

Supporting Online Material can be found at: http://www.sciencemag.org/cgi/content/full/318/5854/1305/DC1

A list of selected additional articles on the Science Web sites related to this article can be found at:

http://www.sciencemag.org/cgi/content/full/318/5854/1305\#related-content

This article cites 22 articles, 6 of which can be accessed for free:

http://www.sciencemag.org/cgi/content/full/318/5854/1305\#otherarticles

This article has been cited by 2 articles hosted by HighWire Press; see:

http://www.sciencemag.org/cgi/content/full/318/5854/1305\#otherarticles

This article appears in the following subject collections:

Neuroscience

http://www.sciencemag.org/cgi/collection/neuroscience

Information about obtaining reprints of this article or about obtaining permission to reproduce this article in whole or in part can be found at:

http://www.sciencemag.org/about/permissions.dtl 
LexA alone, activated a $L a c Z$ reporter gene driven by the LexA operator (Fig. 3A). Two amino acid-substituted FHY3 proteins corresponding to the $f h y 3-9 \mathrm{Gly}^{305} \rightarrow \mathrm{Arg}^{305}$ (G305R) and fhy3-10 $\mathrm{Asp}^{283} \rightarrow \mathrm{Asn}^{283}(\mathrm{D} 283 \mathrm{~N})$ mutant alleles (5) failed to activate the $L a c Z$ reporter gene (Fig. 3A), despite comparable levels of expression for the wild-type and mutant FHY3 fusion proteins. In addition, wild-type FHY3 protein, but not the G305R or D283N mutant proteins, activated a luciferase reporter gene driven by the FHY1 promoter in Arabidopsis protoplasts (Fig. 3B). Further, fusion with the VP16 activation domain of herpes simplex virus restored the transcriptional activation activity of G305R and D283N (Fig. 3A), and the fusion proteins conferred a complete or partial rescue of the fhy 3-4 mutant phenotype (Fig. 3C). These results suggest that the intrinsic transcriptional activation activity of FHY3 is essential for its biological function. Domain deletion analysis revealed that the $\mathrm{C}$-terminal region of FHY3 and FAR1 that lacks the N-terminal zinc finger motif is necessary and fully capable of activating the reporter gene expression in yeast, whereas their N-terminal DNA binding domains are unable to activate the reporter gene (fig. S11). These observations suggest that FHY3 and FAR1 have separable DNA binding and transcriptional activation domains.

Finally, we examined how FR light regulates the expression of FHY3 and FARl using quantitative RT-PCR. In a wild-type background, the transcript levels of FHY3 declined rapidly after exposure to FR light. Expression of FAR1 was also down-regulated by FR light, although with slower kinetics and to a lesser degree (Fig. 4A). Expression of $F H Y 1$ and $F H L$ displayed a pattern similar to that of FHY3 (Fig. 4B), which is consistent with their being the direct target genes of FHY3 and FAR1. In contrast, expression of FHY3 and FARl remained high in the phyA-211 mutant under FR light (Fig. 4, C and D). These results indicate that expression of FHY3 and FAR1 is subject to a negative feedback regulation by phyA signaling and suggest that FHY3 and FAR1 act at a focal point of a feedback loop that maintains the homeostasis of phyA signaling (fig. S12).

Our phylogenetic and functional analyses support a scenario whereby one or several related MULE transposases gave rise to the $\mathrm{FHY}_{3} /$ FAR1-related genes during the evolution of angiosperms through a process termed "molecular domestication" (20), with concomitant loss of the ability to transpose (21) (fig. S13). Similar to this, DAYSLEEPER, an Arabidopsis hAT-like transposase, has been shown to act as a DNA binding protein and is essential for plant development (22). However, it is not known whether this protein can directly regulate gene expression. Our results demonstrate that a transposasederived protein can bind to a promoter region and directly stimulate the transcription of that gene. Innovation of phyA, which occurred before the origin of angiosperms, has been hypothesized to confer an adaptive advantage to the successful colonization of the first angiosperms on Earth (23). The domestication of FHY3 and FAR1 from an ancient transposase(s) might mark an event in the evolution of angiosperms serving to meet the challenges of changing light environments. Our results also provide functional evidence to support the proposition that transposable elements, which are prevalent throughout the genomes of many plants and animals, can serve as a source of new transcription factors that allow populations to adapt and species to evolve (24).

References and Notes

1. M. M. Neff, C. Fankhauser, ]. Chory, Genes Dev. 14, 257 (2000).

2. P. H. Quail, Nat. Rev. Mol. Cell Biol. 3, 85 (2002).

3. F. Nagy, S. Kircher, E. Schäfer, Semin. Cell Dev. Biol. 11, 505 (2000).

4. M. Hudson, C. Ringli, M. T. Boylan, P. H. Quail, Genes Dev. 13, 2017 (1999).

5. H. Wang, X. W. Deng, EMBO J. 21, 1339 (2002).

6. T. Desnos, P. Puente, G. C. Whitelam, N. P. Harberd, Genes Dev. 15, 2980 (2001).

7. Q. Zhou et al., Plant J. 43, 356 (2005).

8. A. Hiltbrunner et al., Curr. Biol. 15, 2125 (2005).

9. A. Hiltbrunner et al., Plant Cell Physiol. 47, 1023 (2006).

10. M. E. Hudson, D. R. Lisch, P. H. Quail, Plant J. 34, 453 (2003).

11. R. Lin, H. Wang, Plant Physiol. 136, 4010 (2004)

12. D. Lisch, Trends Plant Sci. 7, 498 (2002).

13. The accession numbers for Arabidopsis PHYA, FHY3, FAR1, FHY1, FHL, and the maize MURA and the predicted transposase of Jittery are NP_172428, NP_188856, NP_567455, NP_181304, AAC23638, AAA21566, and AAF66982, respectively.
14. M. M. Babu, L. M. Iyer, S. Balaji, L. Aravind, Nucleic Acids Res. 34, 6505 (2006).

15. K. S. Makarova, L. Aravind, E. V. Koonin, Trends Biochem. Sci. 27, 384 (2002)

16. D. Wagner, R. W. M. Sablowski, E. M. Meyerowitz, Science 285, 582 (1999).

17. The effectiveness of $\mathrm{CHX}$ treatment in inhibiting protein synthesis was shown by blocking HY5 protein accumulation in FR light-treated Arabidopsis seedlings (fig. S5). A full description of the materials and methods are available as supporting material on Science Online.

18. T. Yan et al., Nucleic Acids Res. 33, W262 (2005).

19. T. Allen et al., Plant Cell 18, 2506 (2006).

20. W. J. Miller, J. F. McDonald, D. Nouaud, D. Anxolabéhère, Genetica 107, 197 (1999).

21. We observed partial synteny conservation of Arabidopsis FHY3 and FAR1 with their orthologs in Brassica and Populus, suggesting that the genomic locations of these genes have been fixed in the eudicots (fig. S13).

22. P. Bundock, P. Hooykaas, Nature 436, 282 (2005).

23. S. Mathews, J. Hered. 96, 197 (2005).

24. C. Biémont, C. Vieira, Nature 443, 521 (2006).

25. We thank F. Nagy, X. Dong, and P. Fobert for sharing the PHYAp::AtphyA-GFP4 transgenic line, a GR construct, and a VP16 template, respectively; X. W. Deng, G. Martin,

J. Nasrallah, D. Stern, and S. Mathews for commenting on the manuscript; and Z. Fei for helping promoter analysis.

This work was supported by funds from BTI, Triad Foundation, and NSF (IOS-0641639 to H.W. and DBI-0618969 for microscopy facilities at BTI), (to H.W.), University of Texas at Arlington and NIH (R01 GM77582-01 to C.F.), and Microsoft Corporation to CBSU (to D.R.R.).

\section{Supporting Online Material}

www.sciencemag.org/cgi/content/full/318/5854/1302/DC1 Materials and Methods

Figs. $\mathrm{S} 1$ to $\mathrm{S} 13$

Tables $\mathrm{S} 1$ and $\mathrm{S} 2$

References

11 June 2007; accepted 17 October 2007

10.1126/science.1146281

\title{
Social Comparison Affects Reward-Related Brain Activity in the Human Ventral Striatum
}

\author{
K. Fliessbach, ${ }^{1}$ B. Weber, ${ }^{1}$ P. Trautner, ${ }^{1}$ T. Dohmen, ${ }^{2}$ U. Sunde, ${ }^{2}$ C. E. Elger, ${ }^{1}$ A. Falk ${ }^{3 *}$
}

Whether social comparison affects individual well-being is of central importance for understanding behavior in any social environment. Traditional economic theories focus on the role of absolute rewards, whereas behavioral evidence suggests that social comparisons influence well-being and decisions. We investigated the impact of social comparisons on reward-related brain activity using functional magnetic resonance imaging (fMRI). While being scanned in two adjacent MRI scanners, pairs of subjects had to simultaneously perform a simple estimation task that entailed monetary rewards for correct answers. We show that a variation in the comparison subject's payment affects blood oxygenation level-dependent responses in the ventral striatum. Our results provide neurophysiological evidence for the importance of social comparison on reward processing in the human brain.

$\mathrm{T}$ he absolute consumption level, or alternatively the absolute level of income, is the most important determinant of individual well-being in traditional economic models of decision-making. These models typically assume that social comparisons, and therefore relative income, play no role. This view has long been challenged by social psychologists and anthropologists, who have argued that comparison with other individuals 
is a central phenomenon within human societies $(1,2)$. The question of whether social comparison affects individuals' subjective well-being, and thus behavior, is of fundamental importance, with far-reaching implications for the positive and normative predictions of economic theories. Examples include patterns of consumption and savings, the design of optimal taxation and redistribution schemes, labor supply, and the optimal provision of incentives in firms (3-6). Social comparison is also a premise of any model of social preferences, because these theories model fairness judgments and resulting reciprocal responses based on an individual's outcomes relative to the outcomes of relevant others $(7,8)$.

Despite the importance of distinguishing the roles of absolute and relative income levels for subjective well-being, and thus for human decision-making, the underlying neurobiological basis of social comparison is not well understood. One of the reasons is that the role of relative comparison for subjective well-being has mainly been investigated using predicted comparison income from selfreported survey data or actual outcomes of a priori defined reference groups (9). Several methodological problems plague research in this area, including the measurement of relevant incomes and reference groups, the measurement of subjective well-being, and the potential endogeneity of income $(10,11)$. Combining functional magnetic resonance imaging (fMRI) and behavioral experiments allows us to circumvent most of these empirical problems by measuring neurophysiological responses to absolute and relative incomes in the human brain. Brain regions that are engaged in the prediction and registration of rewards include midbrain-striatal and midbrainprefrontal dopaminergic projections (12). Activity in these brain regions is influenced both by primary rewards such as food delivery (13) and by more abstract forms of rewards such as monetary incentives $(14,15)$. We tested the hypothesis that activity in these brain areas increases with higher relative payments. This hypothesis is in contrast to the traditional economic paradigm, which predicts differential activation only in response to changes in one's own rewards but not to changes in others' rewards. In the experiment, two subjects simultaneously and repeatedly performed a simple work task in two adjacent MRI scanners (Fig. 1). Nineteen subject pairs were included, and data from 33 subjects could be analyzed (10). The task involved estimating the number of dots on a screen. At the end of each of 300

${ }^{1}$ Life and Brain Center Bonn, Department of NeuroCognition and Clinic of Epileptology, Bonn, Germany. ${ }^{2}$ Institute for the Study of Labor, Bonn, Germany. ${ }^{3}$ University of Bonn, Department of Economics, Bonn, Germany.

*To whom correspondence should be addressed. E-mail: armin.falk@uni-bonn.de trials, both subjects received a feedback. This feedback provided information about both subjects' performance (whether the estimates were correct or incorrect), as well as about both subjects' payments in a given trial. Payment conditions are illustrated in Table 1. Conditions $\mathrm{C} 1$ to $\mathrm{C} 5$ applied when the estimate of at least one subject was incorrect. These conditions were used to identify reward-sensitive brain regions independently of the conditions of interest, C6 to C11. The latter applied if both subjects solved the task correctly. For these trials, rewards were chosen from a 2 by 3 factorial design in which we varied the absolute level of payment (high versus low) (factor 1) and the relation of a subject's payment to that of the other subject $(1: 2,1: 1$, or 2:1) (factor 2). Our set-up allows us to study the impact of relative payments on reward

Fig. 1. Single-trial settings. Subjects saw a number of blue dots for 1500 ms (screen 1). Immediately afterward, a number was presented and subjects had to decide by button press whether the number of dots on the first screen had been lower or higher within a time limit of 1500 ms (screen 2). After a response feedback ( $250 \mathrm{~ms}$, screen 3) and a short delay (blank screen 4), a feedback screen informed subjects about their and the other subject's performance (correct or incorrect), together with the respective monetary rewards (screen 5).

Table 1. Payoff conditions. Subjects received a payment only if they solved the estimation task correctly. When both subjects' estimates were incorrect, both received nothing (experimental condition (1). When only one of the subjects solved the estimation task correctly, he received either about $30 €$ (low level) or about $60 €$ (high level) while the other received no payment (see conditions $\mathrm{C} 2$ to $\mathrm{C} 5$ ). The conditions of interest (bold) were those in which both subjects solved the estimation task correctly and received payments according to one of the six conditions C6 to C11. These conditions were randomly drawn, and thus occurred with approximately equal frequency. Note that frequencies in conditions $\mathrm{C}_{2,3}$ and $\mathrm{C} 4,5$ are not identical because five subjects were dropped from the analysis.

\begin{tabular}{|c|c|c|c|c|c|}
\hline Accuracy & $\begin{array}{c}\text { Relative } \\
\text { reward } \\
\text { level }(A: B)\end{array}$ & $\begin{array}{c}\text { Absolute } \\
\text { reward } \\
\text { level }\end{array}$ & $\begin{array}{c}\text { Payoffs in Euros } \\
\text { (subject A-subject B) }\end{array}$ & Condition & $\begin{array}{l}\text { Percentage } \\
\text { of occurrence }\end{array}$ \\
\hline $\begin{array}{l}\text { Both subjects } \\
\text { incorrect }\end{array}$ & & & $0-\quad 0$ & $\mathrm{C} 1$ & 6.5 \\
\hline Subject A & & High & $60-$ & $\mathrm{C} 2$ & 14.3 \\
\hline correct & & Low & $30-$ & C3 & \\
\hline Subject B & & High & $0-60$ & $\mathrm{C} 4$ & 13.3 \\
\hline correct & & Low & $0-30$ & $\mathrm{C} 5$ & \\
\hline \multirow{6}{*}{$\begin{array}{l}\text { Both subjects } \\
\text { correct } \\
\text { (conditions of } \\
\text { interest) }\end{array}$} & $1: 2$ & High & $60-120$ & C6 & 65.9 \\
\hline & & Low & $30-60$ & C7 & \\
\hline & 1:1 & High & $60-60$ & C8 & \\
\hline & & Low & $30-30$ & C9 & \\
\hline & $2: 1$ & High & $120-60$ & C10 & \\
\hline & & Low & $60-30$ & C11 & \\
\hline
\end{tabular}

processing in a clean and controlled way: In each trial the task was exactly the same for both subjects, and the subjects knew that. oreover, because both subjects were scanned, stances. Thus, the experimental environment provides no basis or justification for differential ment and is therefore well suited to study ences for the same performance under identical onditions.

$y$ in 81 percent of the trials (SD 0.07), matching almost exactly the intended probaCof correct task performance of 0.8 a functional definition of reward-related structures in our group of subjects independent of a priori information. For this purpose,

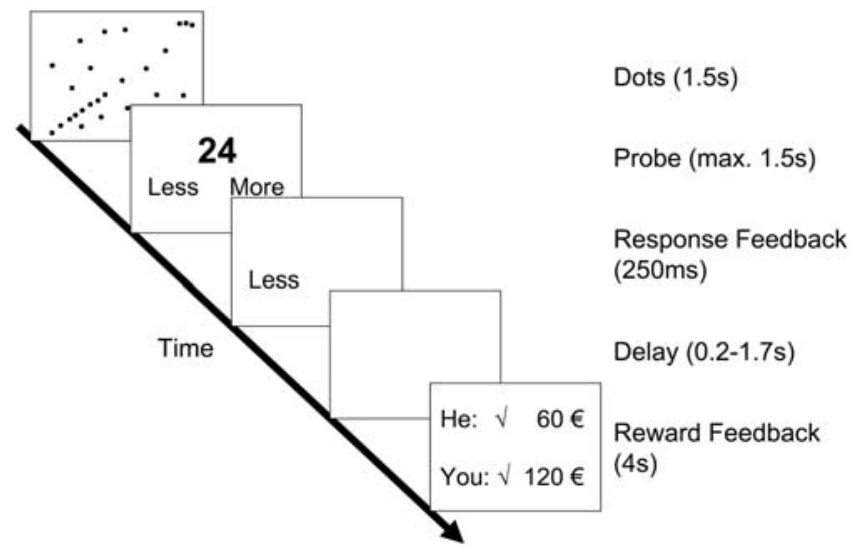


conditions in which a subject solved the task correctly and received a payment while the other subject did not (C2 and C3) were contrasted with conditions in which a subject received no payment $(\mathrm{C} 1, \mathrm{C} 4$, and $\mathrm{C} 5)$. This contrast yielded significant activation in three bilateral and three medial regions, which defined our regions of interest: left and right occipital cortex, left and right angular gyrus, left and right ventral striatum, precuneus, and medial orbitofrontal cortex (two distinct activations) (Fig. 2), thus including the regions known to be critically involved in the processing of reward (12). The opposite contrast (C1,4,5 > $\mathrm{C} 2,3$ ) yielded right and left insular activation, but only when using a less strict threshold (10). Time-course analyses of the blood oxygen level-dependent (BOLD) response showed a strong positive response to the onset of the task (fig. S1). This is consistent with temporal difference models of ventral striatal function, given that the task served as a cue for a possible upcoming reward, thus inducing reward expectation (17). To appropriately model the response
Fig. 2. Glassbrain projection of brain regions showing stronger BOLD responses in conditions in which a subject received a reward while the other did not (C2 and $\mathrm{C} 3$ ) compared with conditions in which a subject did not receive a reward at all $(\mathrm{C} 1, \mathrm{C4}$, and $(5)$.
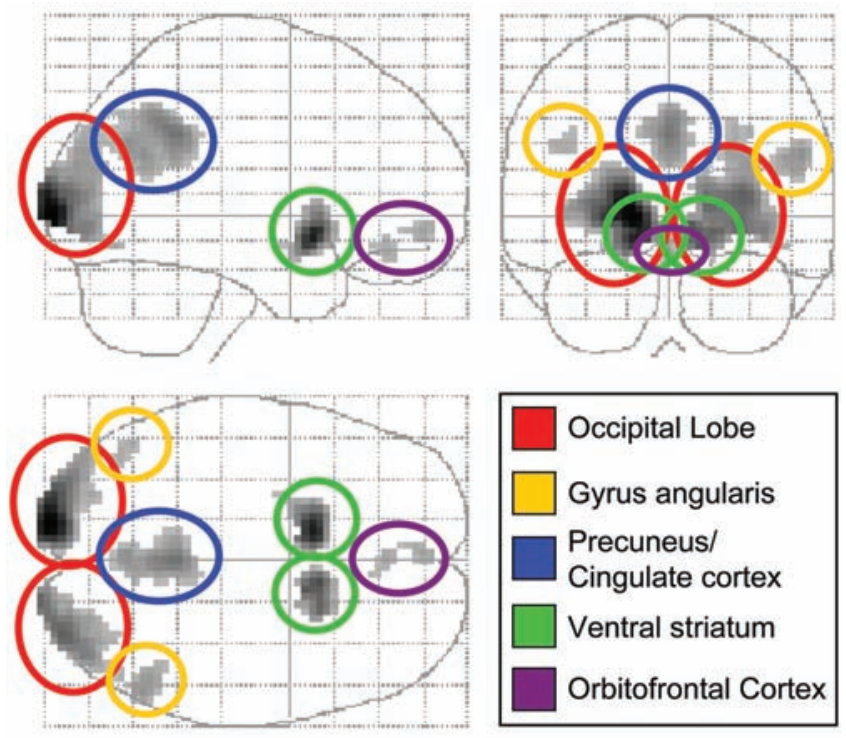

to the reward feedback, we therefore controlled for task-related activity by including task-onset times as an additional regressor in our analysis. The resulting time courses for the reward feedback are shown in Fig. 3C. There is a positive hemodynamic response in conditions $\mathrm{C} 2$ and $\mathrm{C} 3$ (subject receives payment, the other does not) and a decrease of the BOLD signal for conditions $\mathrm{C} 1, \mathrm{C} 4$, and $\mathrm{C} 5$ (subject receives no payment). Intermediate response levels were observed in the conditions of interest in which both subjects received money (C6 to $\mathrm{C} 11$ ). In these conditions, the BOLD signal was strongest when a subject received more than the other subject (2:1), followed by equal payments $(1: 1)$ and trials in which a subject received less than the other subject $(1: 2)$.

In the following, we exclusively analyze the conditions of interest, that is, conditions C6 to C11. For these conditions, we extracted mean parameter estimates for the above-mentioned regions of interest. They were subjected to a 2 by 3 repeated-measurements analysis of variance (ANOVA) with different absolute payment levels (low or high) and relative payments $(1: 2,1: 1$, or $2: 1)$ as factors. In case of bilateral activations, we included the side of the brain as a cofactor. In the ventral striatum, the BOLD response strongly depended on relative payment. The main effect for this factor is: F2,31 $=8.0, P<0.001$. According to our hypothesis, the parameter estimates increased with the ratio between a subject's reward and the other subject's reward: They were lowest for the conditions in which less
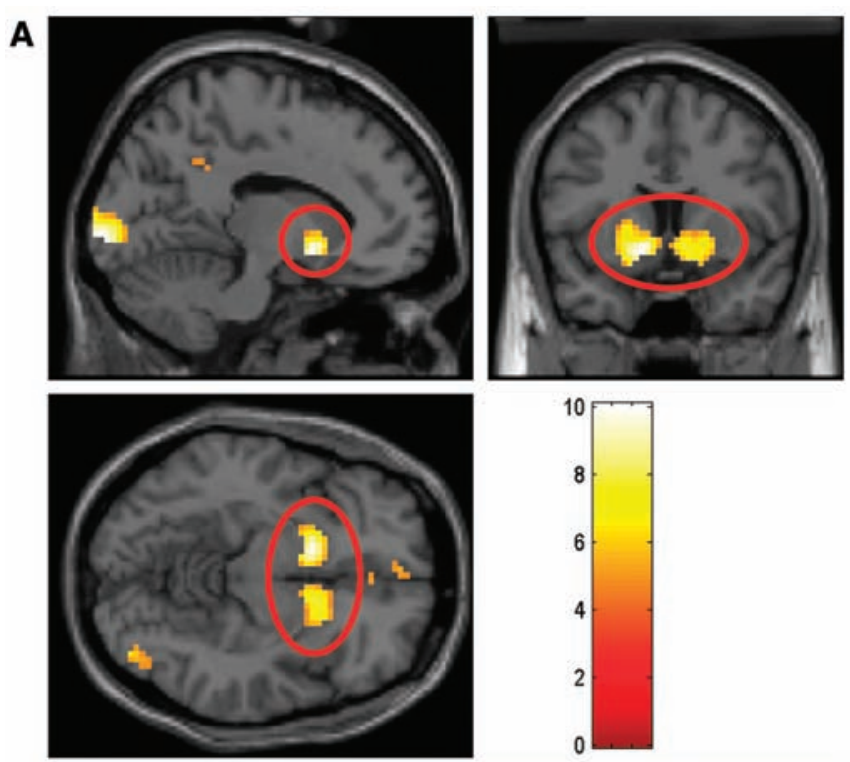

ROI-defining conditions

Conditions of interest (both correct) A's income: B's income

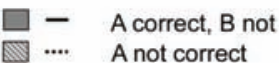

$$
\begin{array}{r}
\square-1: 2 \\
\square-1: 1 \\
-\quad 2: 1
\end{array}
$$

B

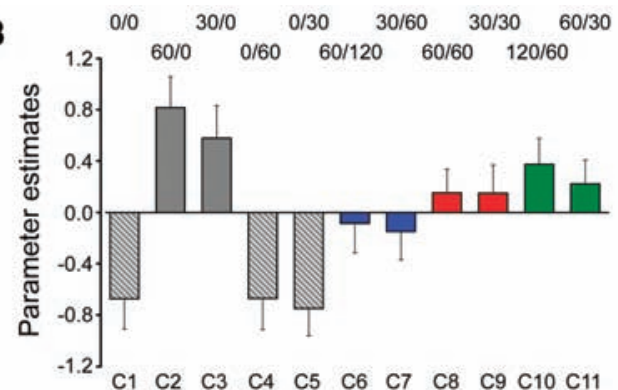

C

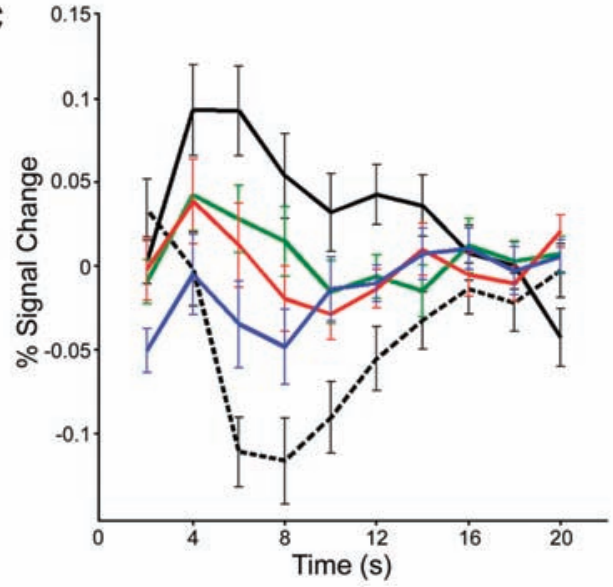

Fig. 3. (A) T-Map projected on a singlesubject template for the contrast between $\mathrm{C} 2$, $\mathrm{C} 3>\mathrm{C} 1, \mathrm{C} 4, \mathrm{C} 5$ with focus on the activation maximum in the left ventral striatum (TAL: $X,-12$; $Y, 8 ; Z, 8)$. (B) Parameter estimates for suprathreshold voxels from this contrast show a dependency of the activation on the relative reward level. (C) Event-related signal changes after the reward feedback collapsed over trials in which a subject received a reward while the other did not (+SEM) (C2, C3, black line), trials where a subject received no reward (C1, C4, C5, black dashed line), and different relative reward levels (1:2, blue line; 1:1, red line; 2:1, green line). 
money was earned, followed by the conditions with equal payment, and were highest in the conditions in which a subject earned more money (Fig. 3B) (see table S2 for means and standard errors). All other main effects and interactions of the ANOVA analysis turn out to be insignificant. This holds for the main effect of high versus low payment condition as well as its interaction with relative payment. The latter result suggests that the importance of relative comparison is independent of the level of payment. In addition, there was no significant impact of the side of the activation or the scanner type. All posterior regions (occipital lobe, angular gyrus, and precuneus/cingulate cortex) showed a different pattern, with response intensity significantly varying with both absolute and relative payment. In these regions, responses were highest for the highpayment condition in the $1: 2$ and the $2: 1$ conditions, that is, in situations when high amounts of money were unequally paid regardless of which of the subjects received more. A similar pattern was found in the two orbitofrontal regions. The posterior of the two orbitofrontal regions additionally showed a significant interaction between absolute and relative payment (table S3 and fig. S2). In the insular regions identified by the contrast $\mathrm{C} 1,4,5>$ $\mathrm{C} 2,3$, activation intensity did not depend on relative or absolute rewards level or an interaction between the two factors (all $P>$ 0.5 ). To test whether, in addition to the regions of interest, other regions were affected by relative comparison, the same ANOVA as described above was run in a whole-brain analysis. The strongest main effect of relative reward level was found in the left and right ventral striatum. The left activation cluster extended into the left amygdala and putamen (fig. S3). In addition, significant activations were found in several bilateral parietal and occipital regions and in the right middle lateral prefrontal cortex (Brodmann areas 8 and 9) (table S4). In contrast to the striatal activations, none of these regions showed a systematic increase of activation with increasing relative income.

Right after the experiment, subjects completed a short questionnaire, which contained questions about willingness to reciprocate kind or unkind actions as well as personality measures (16). Reciprocity is a particularly important type of social preference and is based on the comparison of outcomes relative to those of relevant others (8). In this sense, social comparison is a prerequisite of reciprocal behavior, and we would expect that the more a person is concerned with relative outcomes the more he should be willing to reciprocate. To explore this, we regressed the variability of ventral striatal responses to relative reward differences on the willingness to reciprocate, controlling for personality traits (table S5). This variability turned out to be stronger for subjects who report stronger overall reciprocal inclinations $(t=$ 2.10, $P=0.048)$.

This study shows a relationship between relative income and hemodynamic responses in the ventral striatum. Receiving less than another subject was associated with a reduced BOLD signal in this area. Relative reward processing has previously been demonstrated in the striatum (18) and orbitofrontal cortex (19) of primates, where neuronal responses to a given reward depend on alternative reward outcomes. Similarly, context dependency of ventral striatal responses in humans has been demonstrated with fMRI. Responses to the same rewards differ depending on the sequence of previous rewards and losses $(20,21)$ and on the set of possible outcomes from which the actual reward is chosen $(14,22)$. Our study introduces two critical new aspects of relative reward processing in the ventral striatum. First, it shows that social context is an important factor for reward processing. Second, in contrast to previous studies, the differences in reward activation cannot be explained by a mismatch between expected and received reward.

Whereas in previous studies reward expectation has been manipulated, in our study reward expectation in the conditions of interest should be the same. The differential activation in response to these conditions shows an immediate impact of contextual social information on ventral striatal responses. Although null results in fMRI studies must be interpreted with caution, the fact that no other brain area showed a similar response pattern suggests that this impact is not mediated by brain areas known to be involved in social cognition.

The temporal difference model of ventral striatal function assumes that this brain region is involved in the comparison of predicted and actually received rewards (i.e., reward prediction error) (23). In our study, we find a strong positive response to the onset of the task. We assume that the task serves as a cue for a possible upcoming reward and thus induces reward expectation. Consistent with the temporal difference model, we observed a decrease in the BOLD signal if a subject did not receive a payment and thus reward expectations were not met. Likewise, the BOLD signal increased when a subject was the only one to receive a payment. We hypothesize that outperforming someone else or the "joy of winning" contributes to this response in addition to the monetary reward. For the conditions of interest in which both subjects are correct, the response increases with increasing relative reward. These trials are not confounded with the aspect of winning and losing, because both subjects have solved the same task correctly.

By showing that social comparisons affect activation levels in the ventral striatum, our findings complement recent work on other- regarding preferences such as reciprocity or empathy (24). It has been shown, for example, that reciprocal action in the form of punishing norm violations is associated with ventral striatal activation (25). Similarly, a recent hyperscanning fMRI experiment revealed specific brain activations for benevolent versus malevolent decisions in the dorsal striatum, highlighting the role of this part of the basal ganglia for reciprocal interactions (26). Subjects in these studies made decisions that revealed their preferences. In our study, in contrast, we show that social comparison affects ventral striatal activity even if subjects are not actively engaged in decision-making. In this sense, our study shows that mere contextual information about another person has an immediate impact on motivation-related brain processes.

\section{References and Notes}

1. L. Festinger, Hum. Rel. 7, 117 (1954).

2. J. M. Olson, C. P. Herman, M. P. Zannan (Eds.), Relative Deprivation and Social Comparison (Lawrence Erlbaum, Hillsdale, N], 1986).

3. C. D. Carroll, in Does Atlas Shrug? The Economic Consequences of Taxing the Rich, ]. Slemrod, Ed. (Harvard Univ. Press, Cambridge, 2000).

4. R. Frank, Am. Econ. Rev. 95, 137 (2005).

5. M. J. Boskin, E. Sheshinski, Q. J. Econ. 92, 589 (1978)

6. D. Neumark, A. Postlewaite, J. Pub. Econ 70, 157 (1998)

7. E. Fehr, K. Schmidt, Q. J. Econ. 114, 817 (1999).

8. E. Fehr, S. Gächter, J. Econ. Perspect. 14, 159 (2000)

9. A. Clark, A. Oswald, J. Pub. Econ. 61, 359 (1996).

10. A. Ferrer-i-Carbonell, J. Pub. Econ. 89, 997 (2005)

11. A. Clark, P. Frijters, M. Shields, J. Econ. Lit., in press.

12. J. P. O'Doherty, Curr. Opin. Neurobiol. 14, 769 (2004)

13. J. P. O'Doherty, R. Deichmann, H. D. Critchley, R. ]. Dolan, Neuron 33, 815 (2002)

14. H. C. Breiter, I. Aharon, D. Kahneman, A. Dale, P. Shizgal, Neuron 30, 619 (2001)

15. B. Seymour, N. Daw, P. Dayan, T. Singer, R. Dolan, 1. Neurosci. 27, 4826 (2007)

16. Materials and methods are available as supporting material on Science Online.

17. M. Haruno, M. Kawato, J. Neurophysiol. 95, 948 (2006)

18. H. Cromwell, O. Hassani, W. Schultz, Exp. Brain Res. 162 520 (2005)

19. T. Tremblay, W. Schultz, Nature 398, 704 (1999).

20. R. Elliot, K. J. Friston, R. J. Dolan, J. Neurosci. 20, 6159 (2000)

21. Y. Akitsuki et al., Neuroimage 19, 1674 (2003).

22. S. Niewenhuis et al., Neuroimage 25, 1302 (2005).

23. J. P. O'Doherty, P. Dayan, K. Friston, H. Critchley, R. J. Dolan, Neuron 38, 329 (2003)

24. T. Singer et al., Science 303, 1157 (2004)

25. D. J. F. de Quervain et al., Science 305, 1254 (2004)

26. B. King-Casas et al., Science 308, 78 (2005).

\section{Supporting Online Material}

www.sciencemag.org/cgi/content/full/318/5854/1305/DC1 Materials and Methods

SOM Text

Figs. $S 1$ to $S 3$

Tables $\mathrm{S} 1$ to $\mathrm{S} 5$

References

30 May 2007; accepted 18 October 2007

$10.1126 /$ science.1145876 